\title{
Estimación de costos de establecimiento y producción de papaya en el sur de la Florida en $2012^{1}$
}

\author{
Edward A. Evans, Fredy H. Ballen, y Jonathan H. Crane ${ }^{2}$
}

\section{Introducción}

La papaya se cultiva en más de 60 países alrededor del mundo. La mayor parte de la producción mundial de papaya ocurre en países en vías de desarrollo. Es importante destacar que la producción de papaya es reconocida como un negocio promisorio ya que la fruta se percibe como un alimento muy saludable debido a su elevado contenido de carotenos, vitaminas y flavonoides. Se estima que la producción de papaya a nivel mundial alcanzó 11.22 millones de toneladas en el 2010 (FAOSTAT 2012). Asia es la región que lidera la producción de papaya a nivel mundial con 52.2\% del total; le siguen Suramérica (23\%), África (13.16\%) y Oceanía (0.12\%). Los países que lideran la producción mundial de papaya son India, Brasil, Indonesia, Nigeria y México. Sumados la India y Brasil concentraron el $55 \%$ de la producción mundial de papaya durante el período 2008-2010. México se erige como el principal exportador de papaya y los Estados Unidos como el principal importador de la fruta en el mundo (Evans, Ballen, and Crane 2012).

Estados Unidos no es uno de los grandes productores de papaya. En efecto, su producción alcanzó menos de 15.000 toneladas en 2011, concentrándose fundamentalmente en las islas de Hawái y en menor cuantía en los estados de
Florida, California y Texas. Es importante mencionar que si se considera solamente la parte continental de los Estados Unidos, el estado de la Florida exhibe el mayor potencial para el cultivo de esta fruta. Lo anterior obedece a que las condiciones climáticas de la Florida (tropical/subtropical), favorecen el desarrollo del cultivo a lo largo del año. En Florida se produce papaya madura y verde (inmadura) y la producción de las mismas se concentra al Sur del Estado, específicamente en el condado de Miami-Dade. Actualmente, en el estado de la Florida se estima que existen 300 acres dedicados al cultivo de la papaya, mientras que en la década del setenta el área sembrada era de aproximadamente 500 acres (Balerdi 2012). La disminución en el área dedicada al cultivo de papaya en Florida se atribuye a diversos factores tales como el incremento de la competencia por parte de México y América Central, el incremento en los costos de producción y la introducción de la enfermedad conocida como Virus de la Mancha Anular de la papaya (PRSV, por sus siglas en inglés). Con el fin de permanecer económicamente viables, muchos productores de papaya en los Estados Unidos decidieron intercalar su producción con la de otros cultivos o se enfocaron en el mercado de papaya verde (Inmadura). Este último, es un mercado menos atractivo pues el precio de la papaya verde es la mitad de aquel que se paga por la papaya

1. Éste es el documento EDIS, número FE920, una publicación del Food and Resource Economics Department, Florida Cooperative Extension Service, Institute of Food and Agricultural Sciences, University of Florida. Publicado en febrero de 2013. Visite el sitio web EDIS: http://edis.ifas.ufl.edu.

2. Edward A. Evans, associate professor, and Fredy H. Ballen, economic analysis coordinator, Food and Resource Economics Department, and Jonathan $\mathrm{H}$. Crane, professor, Department of Horticultural Sciences, University of Florida, Tropical Research and Education Center, Homestead, FL.

Los productos químicos deben ser usados de acuerdo con las instrucciones consignadas en las etiquetas de su fabricante. Use los pesticidas de manera segura. Lea y siga las instrucciones de uso en las etiquetas. La mención de marcas registradas en este documento tiene como único objetivo proveer información específica. UF/IFAS no garantiza ni ataca los productos aquí nombrados. Cualquier referencia a un producto específico no excluye a otros productos que tengan el mismo uso y la misma composición. Tampoco sugiere que UF/IFAS los recomienden. 
madura. Adicionalmente, el rendimiento del cultivo decrece (producción por unidad de área) pero tiene el aliciente de un menor costo de producción.

El alza reciente en los precios de la papaya, consecuencia de las restricciones fitosanitarias impuestas a la fruta proveniente de México, ha despertado el interés de productores en el Sur de la Florida, quienes han percibido la oportunidad de suplir la demanda por papaya madura en los Estados Unidos. No obstante, hay mucha incertidumbre con respecto a la viabilidad económica del negocio. El objetivo de este documento es proveer información acerca del retorno económico y los costos de producción de un cultivo de 5 acres de papaya en el Sur de la Florida. Igualmente, se evaluaron precios y rendimientos que permitirían que el negocio fuese rentable en el Sur de Florida.

La información que se presenta en este documento fue obtenida a través de entrevistas con productores, académicos y expertos de la industria. Por lo anterior, esta información debe tomarse como una guía y el lector debe prestar especial interés a los supuestos económicos sobre los cuales se basan los resultados y hacer los ajustes necesarios para su uso. Inclusive, debe anotarse que este artículo no se centra en las prácticas culturales para el cultivo de la papaya, sino en los aspectos económicos de la producción. Aquellos lectores interesados en acceder a información más detallada acerca del manejo del cultivo deben remitirse al documento EDIS PI053 (CIR 1402), titulado Florida Crop/Pest Management Profile: Papaya (Mossler and Crane 2009).

\section{Supuestos utilizados}

Tierra: dado que la mayoría de los cultivadores del Sur de la Florida son dueños de la tierra, se asume una renta anual de $\$ 500 /$ acre con el cual se introduce en el análisis el costo de oportunidad de la tierra. El presupuesto presentado y los costos de producción corresponden a un cultivo de papaya en un área de 5 acres.

Densidad de siembra: La mayoría de las plántulas de papaya que van al campo se obtienen directamente de las semillas. Entre dos y tres semillas se plantan en pequeñas materas (peat pot) y una vez alcanzan una altura de 6 a 8 pulgadas se llevan a campo. Las filas se disponen a una distancia que puede oscilar entre los 12 y los 15 pies, en tanto que la distancia entre plantas que están sobre una misma fila oscila entre los 7 y los ocho pies (Mossler and Crane 2009). Los resultados que se presentan en este estudio corresponden a una disposición en campo de $12 \times 8$ pies entre plantas, lo que equivale a una densidad de 454 plantas por acre. El costo por árbol se estimó en $\$ 0.25$, por ende el costo total del material vegetal es cercano a los $\$ 340(454 \times 3 \times \$ 0.25)$.

Variedades: A pesar de que existen diversas variedades de papaya, las principales variedades que se cultivan en el Sur de la Florida son Red Lady, Tainung-1, y Exp-15.

Fertilización: las encuestas revelaron que los productores de papaya del Sur de la Florida aplican macronutrientes por medio de fertilizantes compuestos (8-3-9, o, 6-6-6), micronutrientes a través de aplicaciones foliares (por ejemplo, manganeso, zinc y boro) y aplican hierro mediante el uso de quelatos de hierro en forma de drench. Debido a la gran diversidad de prácticas de fertilización, en el presente documento se usa el costo promedio.

Control de malezas: en el Sur de la Florida predominan malezas como las gramíneas y las malezas de hoja ancha. El control de las malezas incluye el control químico o la aplicación de herbicida varias veces al año, el desyerbe manual y la poda. El control consiste en la aplicación de algún herbicida cuya base sea el glifosato, en medio de los surcos de papaya. Dicha labor se lleva a cabo en promedio seis veces al año. Adicionalmente se podan los espacios entre surcos de papaya alrededor de seis veces a lo largo del año a un costo de $\$ 120$ por acre. Debido a que las plantas más jóvenes son muy susceptibles al ataque de malezas, es necesario llevar a cabo la labor de desyerbe, principalmente durante los primeros tres a cuatro meses del desarrollo de la planta. Algunos productores cultivan la papaya en camas forradas en plástico y con riego por goteo, cuya altura oscila entre 15-20 centímetros de alto x 1 metro de ancho, 6.8 pulgadas de alto $\mathrm{x} 3$ metros de ancho. El uso de las camas recién mencionadas, disminuye la necesidad de controlar malezas en medio de los surcos de papaya.

Manejo de plagas: las plagas que más afectan al cultivo de papaya en el Sur de la Florida son la mosca de la papaya (Toxotrypana curvicauda), la araña roja (Tetranychus urticae) y la mosca blanca (Bemisia spp). También se consideran plagas de importancia las cochinillas (Philephedra tuberculosa y Paracoccus marginatus), áfidos (Aphididae spp) y el picudo de la raíz (Diaprepes abbreviatus). Adicionalmente, la papaya es susceptible a enfermedades causadas por hongos y virus. Entre las principales enfermedades causadas por hongos están la antracnosis (Colletotrichum gloeosporoides), la mancha gris de la hoja (Corynespora spp), el mildeo polvoriento (Oidium spp) y la marchitez (Phytophthora spp). La principal enfermedad de origen viral es el Virus de la Mancha Anular (PRSV por sus siglas en inglés), la cual es transmitida por los áfidos. El agente causal del PRSV pertenece al grupo de los potyvirus. 
El uso de pesticidas varía ampliamente entre productores, desde aplicaciones cuando se detecta alguna plaga o enfermedad, hasta aplicaciones preventivas llevadas a cabo cada dos a cuatro semanas. Igualmente, existen diversos productos químicos aprobados para el control de plagas en cultivos de papaya (Crane and Mossler 2009). El promedio de costos en control de insectos se estimó en $\$ 356$ para el primer año y $\$ 469$ en el segundo año. Entretanto, el promedio del costo de aplicación de fungicidas se estimó en $\$ 404$ y $\$ 584$ respectivamente, para el primer y segundo año.

Riego: el cultivo de papaya requiere climas cálidos y demanda mucha agua. Es necesario que la planta no se estrese por falta de agua con el fin de evitar problemas como retardo en el crecimiento, abortos florales y caída prematura de los frutos. La mayor parte de los cultivadores entrevistados han instalado sistemas de riego por aspersión o de riego por goteo o utilizan sistemas de riego previamente instalados (por ejemplo de alto caudal con tres aspersores). El costo de irrigación considerado en este trabajo es de $\$ 250$ por acre e incluye, el costo asociado al bombeo del agua, costos de mantenimiento del sistema de riego y el de la mano de obra.

Salarios: Se supuso que la hora de trabajo de un trabajador calificado es de $\$ 15$, mientras que la hora de trabajo de un trabajador de campo se estimó en $\$ 11$. Los valores recién mencionados incluyen beneficios como compensaciones, seguridad social, Medicare y seguro médico.

Cosecha y mercadeo: Para la cosecha se utilizó el pago por unidad (por ejemplo, por caja de papaya cosechada). Cabe anotar que las papayas se cosechan a mano y ocasionalmente se requiere el uso de escalera o elevador hidráulico, si la planta es alta y no se alcanza a cosechar desde el suelo. Los costos correspondientes a cosecha, empaque y transporte se estimaron en $\$ 0.10$ por libra.

Rendimientos: la papaya puede empezar a dar frutos después de 7 a 9 meses de ser trasplantada a su sitio definitivo. De acuerdo con la información proveída por los cultivadores, que se basa en una tasa del $90 \%$ del total de la fruta cosechada (es decir, $10 \%$ de la fruta no cumple con los requisitos de mercado); en el primer año un acre produce en promedio 6,500 libras, en tanto que en el segundo año produce alrededor de 22,500 libras.

Precios: El precio después de empaque de una libra de papaya es de $\$ 0.40$. El cultivador recibe $\$ 0.30$ por libra una vez son descontados los gastos de cosecha, empaque y transporte (farm gate price).
Tasa de interés: La tasa de interés sobre costos previos a la cosecha se estimó en 3\% anual. Nótese que la tasa de interés representa el costo de oportunidad de utilizar los recursos en el cultivo de papaya en lugar de hacerlo en alguna actividad alternativa.

Administración, imprevistos y utilidad (AIU): Estos costos representan otros costos fijos en los que debe incurrir el productor con el fin de operar el negocio, tales como depreciación de la maquinaria, servicios, gastos de oficina, entre otros. Estos costos se estimaron en \$250 al año.

\section{Síntesis de resultados}

A pesar de que el árbol de papaya puede producir fruto por más de 20 años, el ciclo comercial de un árbol de papaya es de dos años (24 meses). La reducción del ciclo de vida de la papaya obedece fundamentalmente al impacto del PRSV. De otro lado, la altura que puede alcanzar el árbol (10 metros/30 pies) se erige como una limitante para las labores de mantenimiento y cosecha (Mossler and Crane, 2009). Es importante destacar que debido a la corta duración del cultivo, no se utiliza aquí el método clásico para estimación de costos en cultivos perennes, consistente en estimar una fase de establecimiento y otra de producción. Por el contrario se utiliza el método de estimación de costos e ingreso correspondiente a cultivos de ciclo corto. Lo anterior implica que costos como la preparación del suelo, material de siembra, siembra y mano de obra requerida para el establecimiento serán considerados como costos variables. La Tabla 1 presenta un resumen de los costos y del retorno del negocio de la papaya en el Sur de la Florida, considerando un acre como la unidad de área. La primera columna de la Tabla 1 muestra los costos y retornos asociados al primer año del negocio, que de alguna manera se puede considerar como el año del establecimiento; en tanto que la segunda columna de la tabla en mención presenta los costos y el retorno del segundo año, el año más productivo. La tercera columna sintetiza costos y retorno del proyecto total (dos años).

La información contenida en la Tabla 1, tercera columna, indica que el costo total de producir y llevar al mercado la papaya proveniente de un acre en el Sur de la Florida es de $\$ 11,322$, equivalente a $\$ 0.39$ por libra. Note que los costos previos a la cosecha (es decir, costo total menos costos de cosecha y mercadeo) se estiman en $\$ 8,422$ por acre (cerca de $\$ 0.29$ por libra) y representan 74.4 por ciento del total del costo de producción.

Los costos variables previos a la cosecha ascienden a $\$ 6,820$ y representan el 60 por ciento del total de costos de producción. Dentro de este rubro los ítems que más pesan 
son fertilizantes (14\%), mano de obra (13\%), fungicidas (9\%), e insecticidas (7\%).

Los costos fijos incluyen la renta de la tierra, impuestos a la propiedad, administración, imprevistos y utilidad se estimaron en $\$ 1,680$ y representan 14 por ciento de los costos de producción. A pesar de que la mayoría de los cultivadores son dueños de la tierra, se incluye una renta de $\$ 500$ que representa el $9 \%$ del total de los costos de producción.

Los costos de cosecha y mercadeo se estimaron en $\$ 2,900$ ( $\$ 0.10$ por libra) y constituyen el 26 por ciento del total del costo de producción. El peso principal del rubro en mención corresponde a al costo de cosecha y empaque de la fruta, en buena medida, debido a que las papayas deben ser cosechadas a mano y manipuladas con sumo cuidado puesto que la fruta es muy susceptible al daño mecánico (Mossler and Crane 2009).

Según los productores entrevistados, el promedio de rendimiento para un acre de papaya es de 29,000 libras en 24 meses (si se asume que el $90 \%$ de la fruta puede ser comercializada). Si se considera que el precio en el lugar de empaque (packing house) es de $\$ 0.40$, el ingreso bruto de la actividad es de $\$ 11,600$ por acre. Si a éste valor se le resta el costo variable, se llega a un margen bruto de $\$ 1880$ por acre $(\$ 11,600-\$ 9,720)$. Este margen permite tener una buena idea de la rentabilidad de corto plazo del negocio. El hecho de que sea positivo indica que el costo variable es cubierto por el ingreso generado y que existe un remanente para cubrir algunos de los costos fijos. En caso de que el margen bruto fuese negativo debería concluirse que este negocio no es viable. Sin embargo, el hecho de no incluir en el margen bruto el costo fijo, no permite tener una idea clara de la rentabilidad de largo plazo del negocio. El beneficio neto se obtiene una vez se resta al margen bruto la cuantía correspondiente a los costos fijos y se constituye en un indicador de la viabilidad de largo plazo del negocio. La tercera columna de la Tabla 1, indica que el beneficio neto del negocio es de $\$ 278$ por acre.

Debido a que el rendimiento (producción por unidad de área) y el precio fluctúan en el tiempo, se llevaron a cabo análisis de sensibilidad para cambios de $10 \%$ en el valor de éstas dos variables, con el fin de considerar su efecto sobre el margen bruto y el beneficio neto (Tabla 2). Un incremento de $10 \%$ en el precio, manteniendo constante el rendimiento $(29,000$ libras por acre) resultaría en un incremento del margen bruto de $\$ 1,880$ a $\$ 3,040$ lo que implica un incremento en el beneficio neto de $\$ 278$ a $\$ 1,438$ por acre. Si se considera que los precios no varían ( $\$ 0.40$ por libra) y que en cambio el rendimiento aumenta en $10 \%$ (31,900 libras por hectárea), el resultado es que el margen bruto incrementa a $\$ 2,750$ mientras que el beneficio neto sería de $\$ 1,148$ por acre. Lo anterior indica que los esfuerzos se deben enfocar en incrementar la porción del precio recibido por el productor, mediante el uso de prácticas (pre y post-cosecha) que aumenten la rentabilidad del negocio.

\section{Conclusiones}

La demanda por papaya en los Estados Unidos ha venido creciendo en razón a diversos factores, entre los que se encuentran el creciente reconocimiento de la fruta como fuente saludable de alimento y el crecimiento de las poblaciones de origen hispano y asiático. Cultivadores de frutas tropicales del Sur de la Florida están a la búsqueda de alternativas rentables y de asegurar que su actividad económica siga siendo viable en el largo plazo. Aun cuando aparentemente se presente la oportunidad de participar del negocio de la papaya en Estados Unidos, debido a la creciente demanda y a las recientes restricciones a las importaciones de papaya desde México (principal fuente de papaya de los Estados Unidos), nuestro análisis revela que el retorno del negocio no es muy atractivo en las condiciones actuales. Nuestro análisis sugiere que la inversión en un acre de papaya asciende a $\$ 11,322$ por acre para un beneficio neto de $\$ 278$ por acre, durante un periodo de dos años. Incluso si uno se concentra exclusivamente en el margen bruto (lo cual no se recomienda), el retorno sería de $\$ 1,880$ por acre, o $\$ 940$ por acre al año. Dado que el productor de papaya es tomador de precios, es necesario que los productores se enfoquen en aumentar su competitividad (disminuir el costo de producción por unidad de producto, e.n., caja de papaya) si se espera que el negocio llegue a ser una alternativa atractiva. De hecho, un incremento de $10 \%$ en el rendimiento del cultivo derivaría en un incremento de más del $300 \%$ en el beneficio neto del proyecto.

Actualmente, los productores están severamente limitados por la presencia de PRSV, dado que limita la producción a máximo dos años, aumentando los costos por unidad. Resultados preliminares (Migliaccio et al. 2010) del Centro Tropical de Investigación y Educación (TREC, por sus siglas en inglés) de la Universidad de la Florida (University of Florida) indican que el uso de una variedad genéticamente modificada de papaya con resistencia al PRSV permitiría a los productores incrementar cuatro veces la producción y extender la vida del cultivo por un año adicional (para un total de tres años) lo cual mejora significativamente la rentabilidad del cultivo de papaya. 


\section{Referencias}

Balerdi, C. 2012. Personal communications.

Crane, J.H., and M.A. Mossler. 2009. Pesticides registered for tropical fruit crops in Florida. Electronic Data Information Source (EDIS) HS177 (HS929). University of Florida, Gainesville, FL. http://edis.ifas.ufl.edu/HS177

Evans, E.A., F.H. Ballen, and J.H. Crane. 2012. An overview of the papaya production, trade, and consumption. Electronic Data Information Source (EDIS) FE914. University of Florida, Gainesville, FL. http://edis.ifas.ufl.edu/FE914

Evans, E.A., and O. Mendoza. 2009. World mango trade and the economics of mango production. In Mango, Botany, Production, and Uses, Second Edition, edited by R. E. Litz, 606-628. Wallingford, UK: CABI Publishing

Migliaccio, K.W., B. Schaffer, J.H. Crane, and F. Davies. 2010. Evapotranspiration and soil water sensor irrigation scheduling methods for papaya production in South Florida. Agricultural Water Management 97:1452-1460.

Mossler, M.A., and J.H. Crane. 2009. Florida crop/pest management profile: Papaya. Electronic Data Information Source (EDIS) PI053 (CIR 1402). University of Florida, Gainesville, FL. http://edis.ifas.ufl.edu/pi053 
Copia de archivo: para las recomendaciones actuales, consulte http://edis.ifas.ufl.edu o su oficina de extensión local.

Tabla 1. Costos de establecimiento y de producción de papaya en el sur de la Florida (un acre)*

\begin{tabular}{|c|c|c|c|c|}
\hline & Unidad & $\begin{array}{c}\text { Año } 1 \\
\text { (establecimiento) }\end{array}$ & $\begin{array}{c}\text { Año } 2 \\
\text { (Mayor Producción) }\end{array}$ & Años $1 \& 2$ Total \\
\hline Rendimiento estimado & lb/acre & 6,500 & 22,500 & 29,000 \\
\hline Precio estimado & $\$ / \mathrm{lb}$ & 0.40 & 0.40 & 0.40 \\
\hline Ingreso bruto & Dólares & 2,600 & 9,000 & 11,600 \\
\hline \multicolumn{5}{|l|}{ COSTOS } \\
\hline Costos pre-cosecha & $\$ /$ acre & & & \\
\hline $\begin{array}{l}\text { Preparación del suelo (arado de disco y } \\
\text { camas) }\end{array}$ & & 100 & & 100 \\
\hline Arboles & & 338 & & 338 \\
\hline Siembra y otros & & 225 & & 225 \\
\hline Riego & & 250 & 250 & 500 \\
\hline Fertilizante & & 663 & 866 & 1,529 \\
\hline Herbicida & & 100 & 200 & 300 \\
\hline Insecticida & & 356 & 469 & 825 \\
\hline Fungicida & & 404 & 584 & 988 \\
\hline Poda & & 120 & 120 & 240 \\
\hline $\begin{array}{l}\text { Trabajo (desyerbe, aplicación de } \\
\text { fertilizante, etc.) }\end{array}$ & & 684 & 812 & 1,496 \\
\hline Mantenimiento & & 40 & 41 & 81 \\
\hline $\begin{array}{l}\text { Interés causado por inversiones pre- } \\
\text { cosecha }\end{array}$ & & 98 & 100 & 198 \\
\hline \multicolumn{5}{|l|}{ Costos de cosecha y mercadeo } \\
\hline Cosecha, empaque y transporte & & 650 & 2,250 & 2,900 \\
\hline Total costos variables y de establecimiento & $\$ /$ acre & 4,028 & 5,692 & 9,720 \\
\hline Margen Bruto & & $(1,428)$ & 3,308 & 1,880 \\
\hline Costo fijo anual & $\$ /$ acre & & & \\
\hline Tierra (precio de arrendamiento) & & 500 & 500 & 1,000 \\
\hline Impuesto a la propiedad & & 50 & 52 & 102 \\
\hline $\begin{array}{l}\text { Administración, Imprevistos y Utilidad } \\
\text { (Overhead) }\end{array}$ & & 250 & 250 & 500 \\
\hline Total Costos Fijos & $\$ /$ acre & 800 & 802 & 1602 \\
\hline COSTOS TOTALES & $\$ /$ acre & 4,828 & 6,494 & 11,322 \\
\hline BENEFICIO NETO & $\$$ /acre & $(2,228)$ & 2,506 & 278 \\
\hline
\end{tabular}


Copia de archivo: para las recomendaciones actuales, consulte http://edis.ifas.ufl.edu o su oficina de extensión local.

Tabla 2. Cambios en el margen bruto y en el beneficio neto, para cambios de $10 \%$ en rendimiento y precios, según combinación de precio y rendimientos

\begin{tabular}{|c|c|c|c|c|c|c|}
\hline \multirow[t]{3}{*}{ Yield (lb/acre) } & \multicolumn{6}{|c|}{ Precio (\$/lb) F.O.B. Homestead } \\
\hline & 0.36 & 0.40 & 0.44 & 0.36 & 0.40 & 0.44 \\
\hline & \multicolumn{3}{|c|}{ Margen Bruto (\$/acre) } & \multicolumn{3}{|c|}{ Beneficio Neto (\$/acre) } \\
\hline 26,100 & $(-34)$ & 1,010 & 2,054 & $(1,636)$ & $(592)$ & 452 \\
\hline 29,100 & 702 & 1,880 & 3,040 & $(882)$ & 278 & 1,438 \\
\hline 31,900 & 1,474 & 2,750 & 4,026 & $(128)$ & 1,148 & 2,424 \\
\hline
\end{tabular}

